\title{
After All, It was Not Lung Cancer: When The Evidence is Misleading
}

\author{
$\underline{\text { Joana Braga }}{ }^{1}$, Francesca Pereira ${ }^{1}$, Cristiana Fernandes $^{1}$, Marinha Silva $^{1}$, Cristina Marques $^{1}$, Daniela Alves $^{2}$, Carlos Oliveira $^{1}$ \\ ${ }^{1}$ Department of Internal Medicine, Hospital Santa Maria Maior, Braga, Portugal \\ ${ }^{2}$ Department of Pneumology, Hospital Santa Maria Maior, Braga, Portugal
}

Received: 25/02/2021

Accepted: $11 / 03 / 2021$

Published: $12 / 04 / 2021$

How to cite this article: Braga J, Pereira F, Fernandes C, Silva M, Marques C, Alves D, Oliveira C. After all, it was not lung cancer: when the evidence is misleading. EJCRIM 2021;8: doi:10.12890/2021_002422.

Conflicts of Interests: The Authors declare that there are no competing interests.

This article is licensed under a Commons Attribution Non-Commercial 4.0 License

\section{ABSTRACT}

The aetiology of pulmonary nodules is varied, with malignant lesions being the most important and requiring rapid diagnosis and treatment. However, although clinical presentation and imaging may suggest a specific diagnosis, it should be kept in mind that some benign pathologies mimic more serious disease.

A 50-year-old man presented with left pleuritic chest pain. A CT scan showed an ipsilateral pulmonary spiculated nodule. Pneumonia was assumed and the patient was started on antibiotic therapy. In the absence of improvement, positron emission tomography and a transthoracic aspiration biopsy were performed. Lung cancer was diagnosed and the patient underwent an upper lobectomy. However, examination of the surgical specimen showed no malignancy.

\section{LEARNING POINTS}

- Although complementary diagnostic exams are increasingly available and widely used, they may produce false positive or false negative results.

- A correct diagnostic approach can lead to an incorrect diagnosis.

- The preoperative diagnosis of pulmonary nodules can be a challenge.

\section{KEYWORDS}

Pulmonary nodule, parasitic infection, non-small cell lung cancer

\section{CASE DESCRIPTION}

A 50-year-old male farmer presented to the emergency department. His personal history was not relevant, and he did not smoke or drink alcohol. He was not taking any chronic medication and had no known allergies.

The patient complained of pain in the middle third of the left hemithorax, which had started about 2 hours previously as he was walking, with pleuritic characteristics and no radiation. He also had a 3-week history of asthenia on medium effort. Fever, cough, sputum, haemoptysis and constitutional symptoms were denied. The physical examination was unremarkable. Acute coronary syndrome was excluded as an electrocardiogram showed no evidence of ischaemia and myocardial necrosis markers were not elevated. Blood analysis showed no leucocytosis or eosinophilia, mild neutrophilia, ESR $10 \mathrm{~mm} / \mathrm{hr}$, and C-reactive protein $1.40 \mathrm{mg} / \mathrm{dl}$, with no other changes.

Thoracic radiography revealed a peripheral nodule in the left pulmonary field (Fig. 1). For better lesion characterization, a chest CT scan was performed which showed a $3 \mathrm{~cm}$ pulmonary consolidation with irregular and spiculated margins, an air bronchogram in the periphery of the upper segment of the lingula (Fig. 2), and a small lytic lesion in the T9 right hemibody. Since malignancy could not be excluded, short-term surveillance was started after the initiation of antibiotic therapy with amoxicillin/clavulanic acid and azithromycin. 

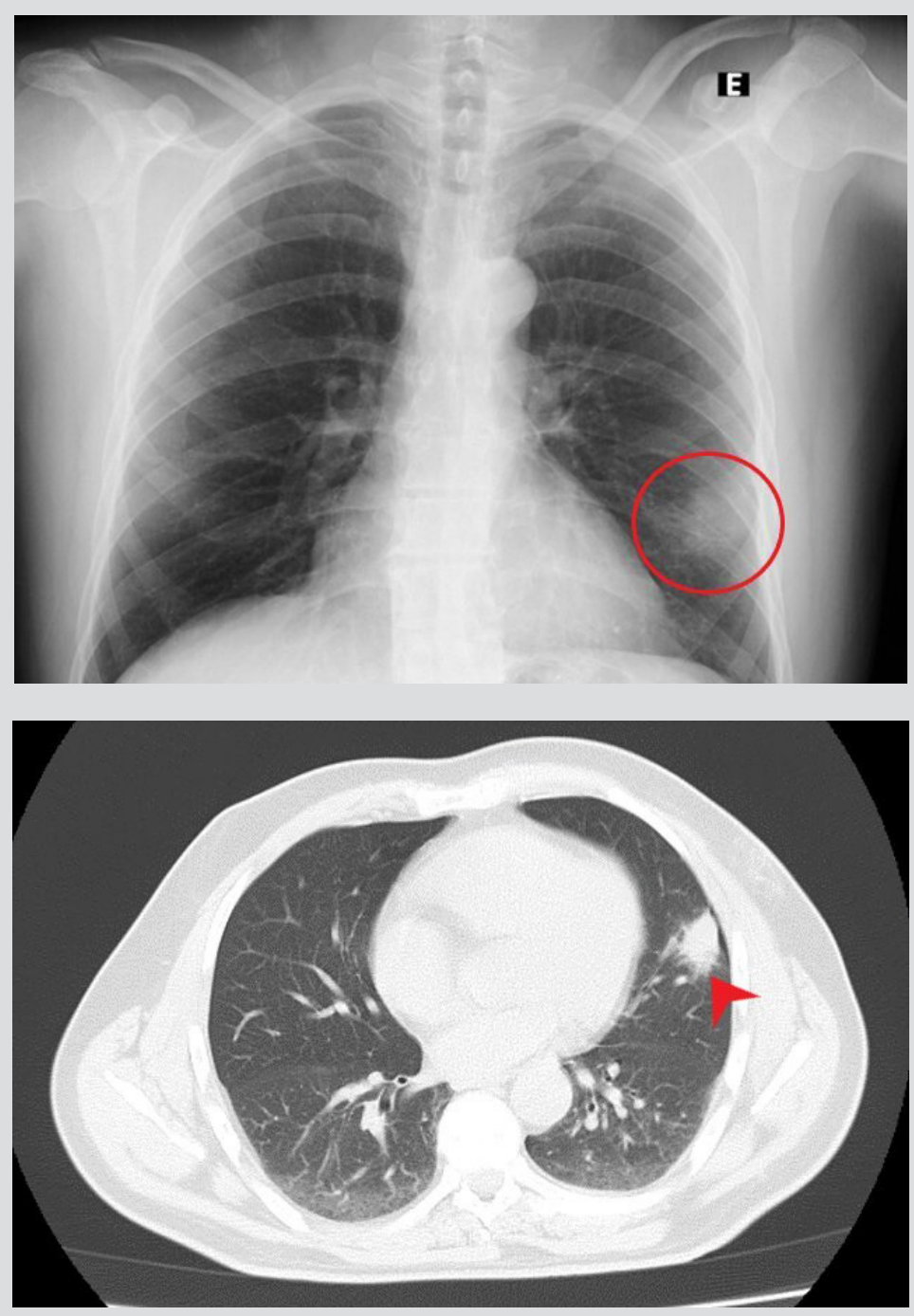

Figure 1. Thoracic radiograph on admission showing lung lesion on the left (red circle)

Figure 2. Thoracic CT scan showing a $3 \mathrm{~cm}$ pulmonary consolidation with irregular and spiculated margins (red arrow)

In the absence of improvement, and given the hypothesis of a neoplastic lesion, PET was performed, which revealed a focus of nodular uptake in the left lung lingula (Fig. 3A), and a photopenic lesion in the T9 vertebral body related to a non-specific lytic lesion (Fig. 3B). Spinal MRI excluded metastatic bone lesions, and suggested the T9 lesion was compatible with a lipohemangioma .

A transthoracic aspiration biopsy was then performed, the result of which was compatible with non-small cell lung carcinoma. Thus, in view of these findings, the patient underwent lobectomy of the left upper lobe. Anatomopathological examination of the surgical specimen revealed a necrotic structure with characteristics compatible with parasitic infection and extensive lesions of organizing pneumonia, but no signs of malignancy. The patient remained asymptomatic and was discharged home.

\section{DISCUSSION}

Surgical removal of all lung lesions identified on chest x-ray was common 50 years ago, given the possibility of malignancy, limited knowledge, lack of complementary diagnostic tests, and few therapeutic possibilities.

When a pulmonary nodule is found, the most important thing is to establish the probability of malignancy because of the implications for diagnosis and treatment ${ }^{[1,2]}$. The probability is based on clinical impression, the imaging characteristics of the lesion and a quantitative assessment using a validated prediction model (e.g., the Solitary Pulmonary Nodule Malignancy Risk calculator of the Mayo Clinic, or the Veterans Affairs model) ${ }^{[1-4]}$.

When the pretest probability of malignancy is low $(<5 \%)$, serial surveillance by chest CT is recommended. If the pretest probability is moderate (5-60\%), then CT should be complemented with functional imaging, preferably positron emission tomography (PET). If the nodule is hypermetabolic, non-surgical biopsy is recommended ${ }^{[1,2,4]}$. 

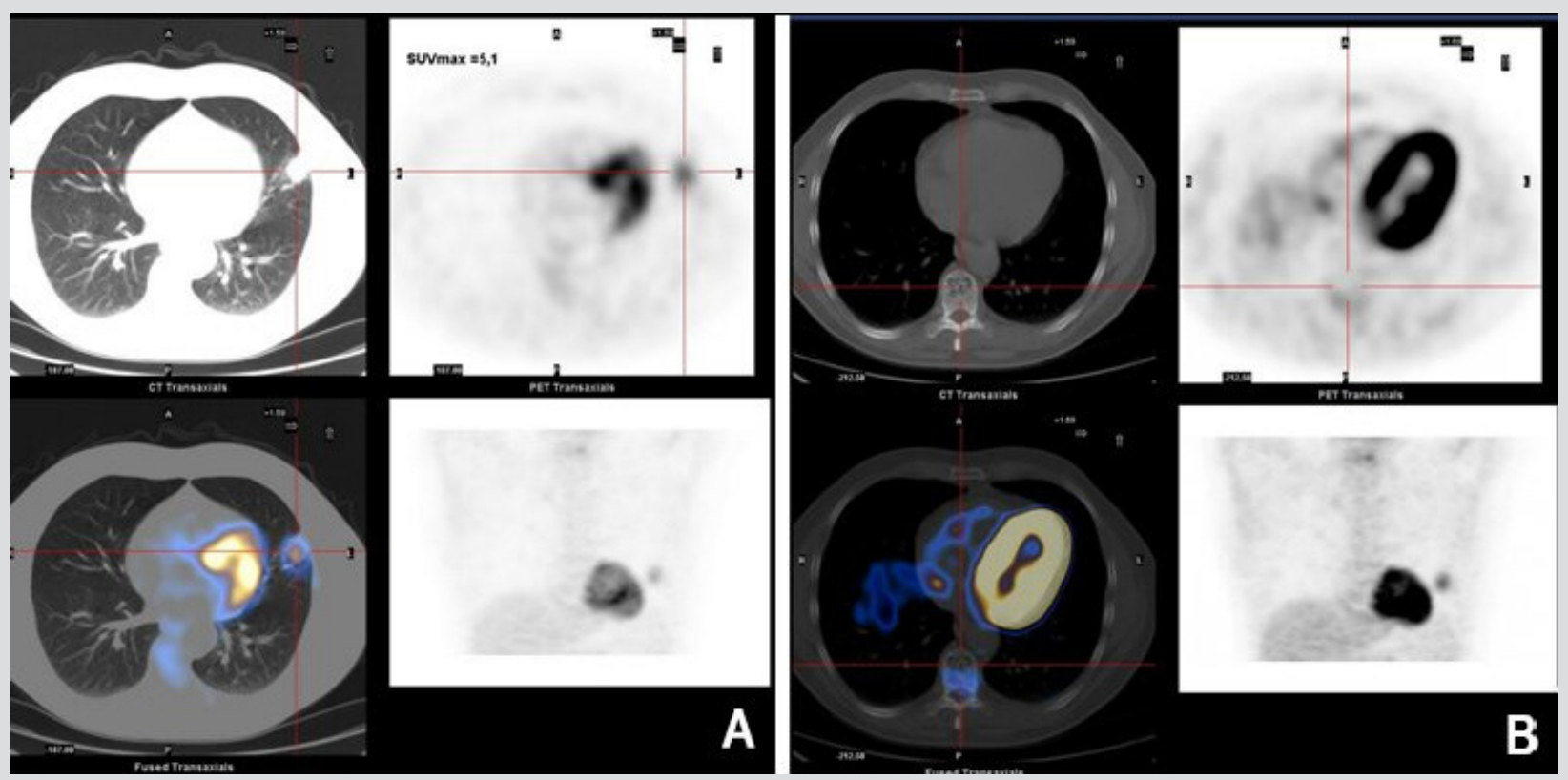

Figure 3. (A) Focus of nodular uptake in the left lung lingula; (B) photopenic lesion in the vertebral body of T9 related to a non-specific lytic lesion

Complementary diagnostic tests have different diagnostic accuracy and limitations, and can provide false positive or false negative results. CT with contrast for pulmonary nodules has a sensitivity of $98 \%$ and specificity of $58 \%$; the absence of nodule enhancement suggests a benign diagnosis with a negative predictive value of $96.5 \%$. PET is widely used for neoplasm diagnosis, staging and assessing response to treatment. It has a sensitivity and specificity of $87-96.8 \%$ and $77.8-83 \%$, respectively ${ }^{[5,6]}$. The biggest problem with PET is false positive results, which can occur in the context of infection and inflammation, which are quite frequent conditions ${ }^{[5]}$.

CT-guided percutaneous transthoracic biopsy is an important tool for the differential diagnosis of pulmonary nodules. Its sensitivity varies from $80 \%$ to $95 \%$ depending on nodule and needle size and the number of samples, with specificity ranging from $50 \%$ to $88 \%{ }^{[6]}$.

In malignant lesions, the results of transthoracic aspiration biopsy have a positive predictive value of $99.2 \%$ and a negative predictive value $96.6 \%{ }^{[5,6]}$. However, they can be inconclusive in about $4-41 \%$ of cases, particularly in benign (44\%) compared with malignant lesions (8\%) ${ }^{[5]}$. Surgical resection is recommended if malignancy is confirmed. If a definitive diagnosis of malignancy cannot be established, surgical excision can be considered if the clinical probability of malignancy is high (the nodule shows increased metabolic activity on PET), the cytological results of the biopsy suggest malignancy, and the fully informed patient requires a definitive diagnostic procedure ${ }^{[4]}$.

In our case, the pulmonary nodule was initially assumed to be an infection, so antibiotics were started. However, it had suspicious characteristics prompting a PET scan, which showed a hypermetabolic lesion, while transthoracic aspiration biopsy results supported the hypothesis of non-small cell lung cancer. However, the surgical specimen had no signs of malignancy.

The differential diagnosis of pulmonary nodules is based both on complementary exams and on the clinical situation. In fact, there is no single test that is ideal for the differential diagnosis of pulmonary nodules since the tests have different limitations, but they do complement each other. Thus, complementary diagnostic tests should be carried out in a step-by-step approach, with surgery not the first option in most cases.

\section{REFERENCES}

1. Libby DM, Smith JP, Altorki NK, Pasmantier MW, Yankelevitz D, Henschke Cl. Managing the small pulmonary nodule discovered by CT. Chest 2004;125(4):1522-1529. Available from: http://dx.doi.org/10.1378/chest.125.4.1522

2. Patro M, Gothi D, Sah RB, Vaidya S. An interesting case of incidental solitary pulmonary nodule. Breathe 2018;14(4):e128-133.

3. Yang W, Sun W, Li Q, Yao Y, Lv T, Zeng J, et al. Diagnostic accuracy of CT-guided transthoracic needle biopsy for solitary pulmonary nodules. PLoS One 2015;10(6):1-9.

4. Dziedzic R, Rzyman W. Incidentally diagnosed pulmonary nodules: a diagnostic algorithm. Kardiochir Torakochirurgia Pol 2014;11(4):397-403.

5. Gould MK, Fletcher J, lannettoni MD, Lynch WR, Midthun DE, Naidich DP, et al. Evaluation of patients with pulmonary nodules: when is it lung cancer? ACCP evidence-based clinical practice guidelines (2nd edition). Chest 2007;132(3 Suppl):108S-130S. Available from: http://dx.doi.org/10.1378/chest.07-1353

6. Baglio PT, Gazzana MB, Silva DR. Nódulo pulmonar solitário. Rev Soc Bras Clín Méd 2009;7:132-139. 